\title{
Challenges of accessing emergency contraceptive pills in Japan
}

For many Japanese women and girls who are at risk of unintended pregnancies, access to emergency contraceptive pills (ECPs) is limited. Obtaining ECPs is very difficult in Japan because they require a prescription and are expensive as they are not covered by the national health insurance. ${ }^{1}$ The Ministry of Health, Labour and Welfare (MHLW) recognised this and debated whether or not to approve overthe-counter (OTC) access that does not require a prescription. Although 92\% of public comments were supportive of ECPs being made available OTC, the MHLW did not approve the change because of some concerns around the uncertainty of ECP effectiveness, misuse and abuse. ${ }^{2}$ However, according to the World Health Organization, ECPs are safe and effective medicines that all health systems should provide in view of the right of women and girls of reproductive age to access ECPs and avoid unintended pregnancies. ${ }^{3} 4$ In Japan, while the number of births in 2016 was 976978, the annual number of unintended pregnancies was estimated to exceed 610000 . Additionally, because cases of unintended pregnancy and sexual violence are increasing, especially in the era of the coronavirus disease pandemic, the issue of ECPs availability needs to be addressed. $^{15}$

In Japan, levonorgestrel-only ECPs (LNG ECPs) and copper-bearing intrauterine devices (IUDs) are the currently available emergency contraception (EC) methods for women and girls. Since May 2011, LNG ECPs have been sold in Japan as NORLEVO TABLETS 1.5 mg' by ASKA Pharmaceutical Co., Ltd. 
(Tokyo, Japan) alone, until the generic label was sold in March 2019. We investigated trends in the use of LNG ECPs in Japan to identify the relationship between the accessibility and use of ECPs (our methods are outlined in the online supplemental methods). After the MHLW approved LNG ECP use in 2011, ECP use increased among women aged 18-39 years, comprising $0.08 \%$ of all women and girls of reproductive age in Japan (figure 1).

Conversely, in the United States (US), LNG ECPs have been available via prescription since 1999, while OTC access without age restriction was permitted in 2013. With the increased accessibility of OTC ECPs, the percentage of women in the US who use these medications increased from $0.8 \%$ in 1995 to $20 \%$ in 2015 (figure 1). In Japan, 160000-180000 abortions are performed annually; ${ }^{5}$ therefore, it is necessary to provide EC options, disseminate accurate information regarding EC using mass media, and provide sex education for teenagers. ${ }^{6}$ To our knowledge, there are no data concerning the amount of knowledge Japanese teenagers have about EC, and obtaining this information seems important for further research on this subject. Similar to the increasing use of LNG ECPs in the US, the approval of OTC sale of ECPs could increase the accessibility and use of ECPs in Japan.

Other EC options, including copperbearing IUDs and the generic LNG ECP, are not discussed here. Since 2004, copper-bearing IUDs ('NOVA-T380') have been exclusively sold by Bayer Yakuhin, Ltd. (Osaka, Japan) in Japan, but the number of shipments is only a few thousand annually. Therefore, we excluded copper-bearing IUDs from our study because of their less common use compared with ECPs.

To date, 19 countries allow direct OTC access to EC and 76 countries allow individuals to obtain ECPs from a pharmacist without a prescription. ${ }^{1}$ Therefore, among developed countries, Japan may appear backward concerning its sexual and reproductive health policies and rights. We hope that the MHLW will approve ECPs as OTC medications, and continue its efforts to improve access to ECPs and thus preserve the rights of women and girls in Japan.

\section{Kyosuke Kamijo $\odot,{ }^{1}$ Yuki Kataoka, ${ }^{2,3}$ Daisuke Shigemi $^{4}$}

${ }^{1}$ Department of Obstetrics and Gynecology, lida Municipal Hospital, lida, Japan

${ }^{2}$ Department of Internal Medicine, Kyoto Min-Iren Asukai Hospital, Kyoto, Japan

${ }^{3}$ Systematic Review Workshop Peer Support Group (SRWS-PSG), Osaka, Japan

${ }^{4}$ Independent Researcher, Tokyo, Japan

Correspondence to Dr Kyosuke

Kamijo, Department of Obstetrics and Gynecology, Iida Municipal Hospital, Iida 395-8502, Japan; m10025kk@jichi. ac.jp

Twitter Kyosuke Kamijo @kkobgyn

Acknowledgements The authors thank ASKA Pharmaceutical Co., Ltd. for providing sales quantity information for NORLEVO TABLETS $1.5 \mathrm{mg}$ and Bayer Yakuhin, Ltd. for providing sales quantity information for NOVA-T380. These companies were not involved in the study design, study analyses, data interpretation, and writing of the manuscript.

Contributors KK analysed the data and drafted the manuscript. YK designed and initiated the study and was the key manuscript reviewer. DS commented on the manuscript and was the key manuscript reviewer. All authors edited the manuscript and approved the final version.

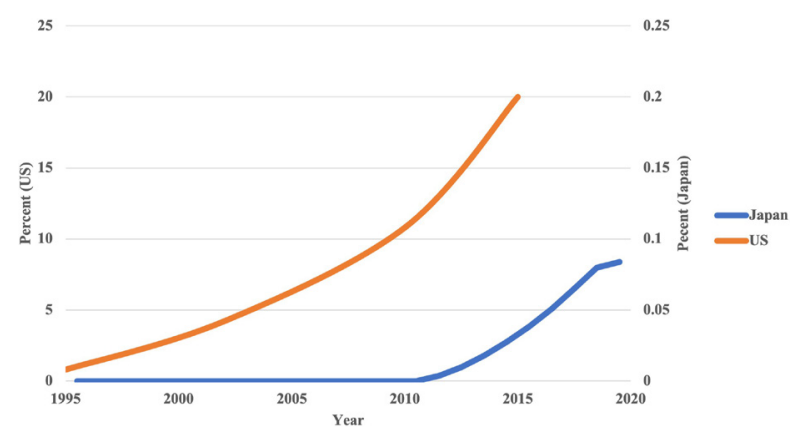

Figure 1 Japan: proportion of cumulative use of emergency contraceptive pills (ECPS) among women aged 18-39 years who have ever had sexual intercourse (online supplement methods). United States (US): proportion of women who have ever used ECPs among women aged 15-44 years who have ever had sexual intercourse (online supplement methods).

Funding The authors have not declared a specific grant for this research from any funding agency in the public, commercial or not-for-profit sectors.

Competing interests None declared.

Patient and public involvement Patients and/or the public were not involved in the design, or conduct, or reporting, or dissemination plans of this research.

Patient consent for publication Not required.

Provenance and peer review Not commissioned; externally peer reviewed. (C) Author(s) (or their employer(s)) 2021. No commercial re-use. See rights and permissions. Published by BMJ.

- Additional supplemental material is published online only. To view, please visit the journal online (http://dx.doi.org/10.1136/bmjsrh-2021-201101).

\section{A) Check for updates}

Published Online First 25 May 2021

BMJ Sex Reprod Health 2021;47:232-233. doi:10.1136/bmjsrh-2021-201101

\section{ORCID iD}

Kyosuke Kamijo http://orcid.org/00000001-7375-7651

\section{REFERENCES}

1 Sorano S, Emmi S, Smith C. Why is it so difficult to access emergency contraceptive pills in Japan? Lancet Reg Health West Pac 2021;7:100095.

2 Ministry of Health, Labor and Welfare. The result of the review conference on the appropriateness switch OTC of emergency contraception pills [in Japanese], 2017. Available: https://www. mhlw.go.jp/file/05-Shingikai-11121000Iyakushokuhinkyoku-Soumuka/ 0000184935.pdf [Accessed 21 Feb 2021].

3 World Health Organization. Emergency contraception, 2018. Available: https:// www.who.int/news-room/fact-sheets/ detail/emergency-contraception [Accessed 21 Feb 2021].

4 World Health Organization. World Health organization model list of essential medicines. mental and holistic health: some international perspectives, 2019: 46-7.

5 Osuga Y, Akiyama S, Murata T, et al. Economic burden of unintended pregnancies in Japan. Iryo To Shakai 2019;29:295-311.

6 Kavanaugh ML, Williams SL, Schwarz EB. Emergency contraception use and counseling after changes in United States prescription status. Fertil Steril 2011;95:2578-81. 